\title{
Pressure gradient prediction in aortic coarctation using a computational-fluid-dynamics model: validation against invasive pressure catheterization at rest and pharmacological stress
}

\author{
Julio A Sotelo ${ }^{1,2^{*}}$, Israel Valverde ${ }^{3,4}$, Philipp B Beerbaum ${ }^{5}$, Gerald F Greil ${ }^{6}$, Tobias Schaeffter ${ }^{6}$, Reza Razavi ${ }^{6}$, \\ Daniel E Hurtado ${ }^{7}$, Sergio Uribe ${ }^{1,8}$, Carlos A Figueroa ${ }^{6,9}$
}

From 18th Annual SCMR Scientific Sessions

Nice, France. 4-7 February 2015

\section{Background}

Aortic Coarctation (AoCo) accounts for $5-8 \%$ of the children with CHD. Even after successful early repair, life expectancy is still markedly reduced $(80 \%$ at 50 years after surgery) compared to normal population due to long term complications (hypertension). Usually, invasive diagnostic catheter investigations are required to evaluate the pressure gradient across the aorta at rest, or unmask such a gradient by use of isoprenaline stress to mimic physical exercise. The application of imagebased computational fluid dynamics (CFD) in patients with AoCo appears promising as an alternative noninvasive diagnostic tool, as it may allow the avoidance of cardiac catheterization to determine pressure gradients. The motivation of this research is to know if a MRI based CFD model can accurately predict the pressure

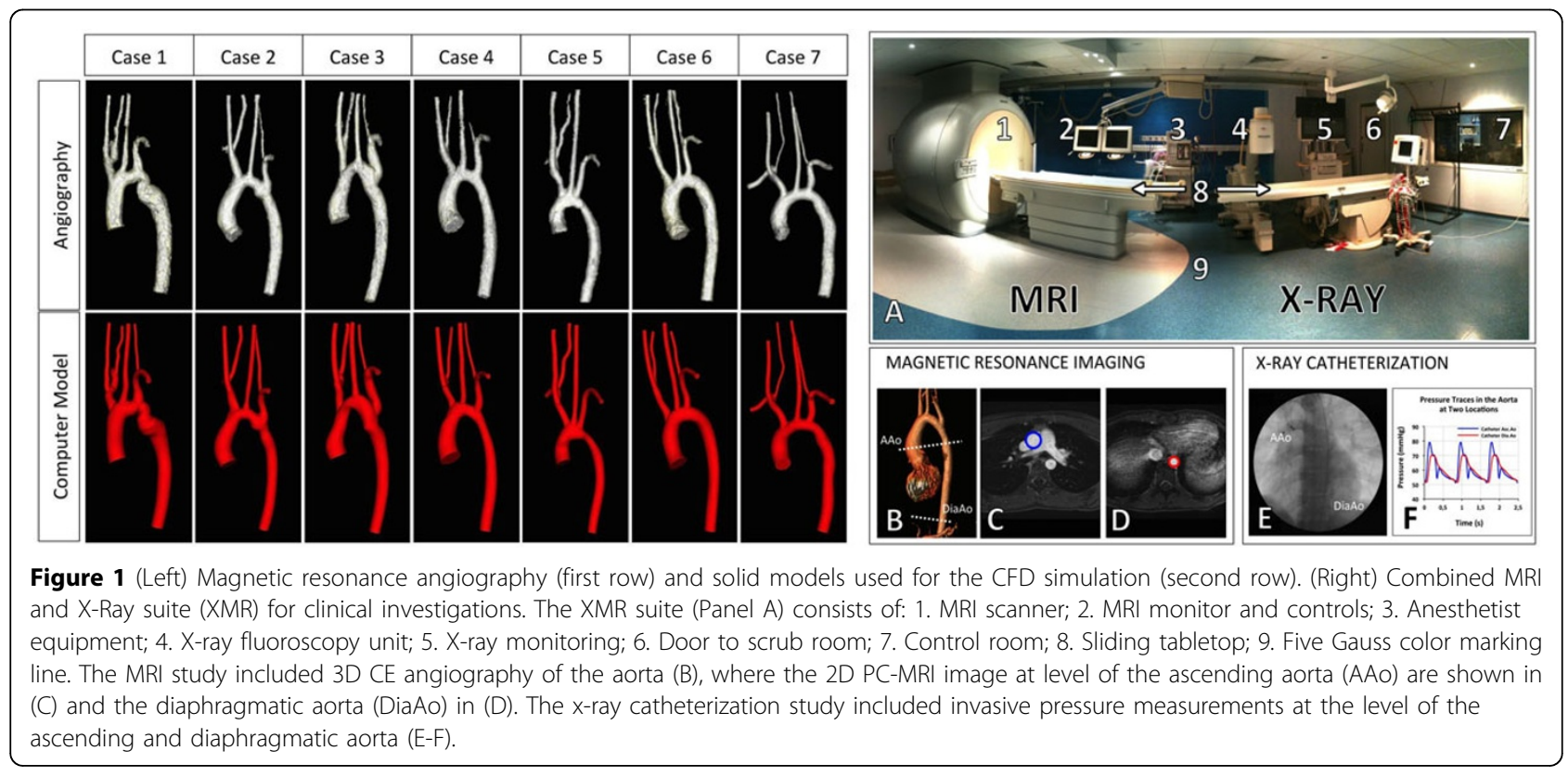

'Biomedical Imaging Center, Pontificia Universidad Católica de Chile,

Santiago, Chile

Full list of author information is available at the end of the article 
gradient in patients with AoCo and therefore be incorporated in the clinical practice.

\section{Methods}

The study included 7 cases with aortic coarctation (mean \pm standard deviation; age 19.4 \pm 4 .6years, weight $71.9 \pm 17.1 \mathrm{~kg})$ (Fig. 1-Left), who had a previous combined MRI (3D CE-MRA, Fig. 1B, and 2D CINE-PC in the ascending and diaphragmatic aorta, Fig. 1C-D) and cardiac catheterization (Two femoral artery catheterization Fig. 1-Right) in a 1.5T Intera MRI scanner and BT Pulsera cardiac radiography unit, Philips, Best, Netherlands. The 3D CE-MRA data was used to create CFD models of the aorta (Fig. 1-Left) using SimVascular (simtk.org) and MeshSim (Simmetrix, Clifton Park, NY). The boundary condition (flows and stiffness distribution) of CFD was setting using the 2D PC-MRI and pressure data.

\section{Results}

The pressure gradients obtained in REST were in good agreement with the ones obtained from catheterization Fig. 2. The mean-to-mean pressure gradient averaged between all cases was $2.85 \pm 2.47 \mathrm{mmHg}$ for the catheterization and $2.76 \pm 1.64 \mathrm{mmHg}$ for the simulation. The peak-to-peak pressure gradient, averaged between all cases was $10.36 \pm 6.54 \mathrm{mmHg}$ for the catheterization and
$9.77 \pm 6.39 \mathrm{mmHg}$ for the simulation. In STRESS the mean-to-mean pressure gradient averaged between all cases was $12.59 \pm 8.61 \mathrm{mmHg}$ for the catheterization and $11.25 \pm 7.60 \mathrm{mmHg}$ for the simulation. The peak-to-peak pressure gradient, averaged between all cases of 52.71 $\pm 22.11 \mathrm{mmHg}$ for the catheterization and 37.38 $\pm 21.64 \mathrm{mmHg}$ for the simulation (Fig. 2).

\section{Conclusions}

In conclusion, we can predict the non-invasive pressure gradient with a good agreement using CFD simulation and cardiovascular magnetic resonance imaging, with the purpose that in the future incorporate this process in the clinical practice.

\section{Funding}

European Research Council under the European Union's Seventh Framework Programme (FP/2007-2013) / ERC Grant Agreement n. 307532, the United Kingdom Department of Health via the National Institute for Health Research (NIHR) comprehensive Biomedical Research Centre award to Guy's \& St Thomas' NHS Foundation Trust in partnership with King's College London and King's College Hospital NHS Foundation Trust. FONDECYT \#1141036 and \#11121224. JS thanks CONICYT and Ministry of Education of Chile, with his higher education program, for scholarship for doctoral studies.

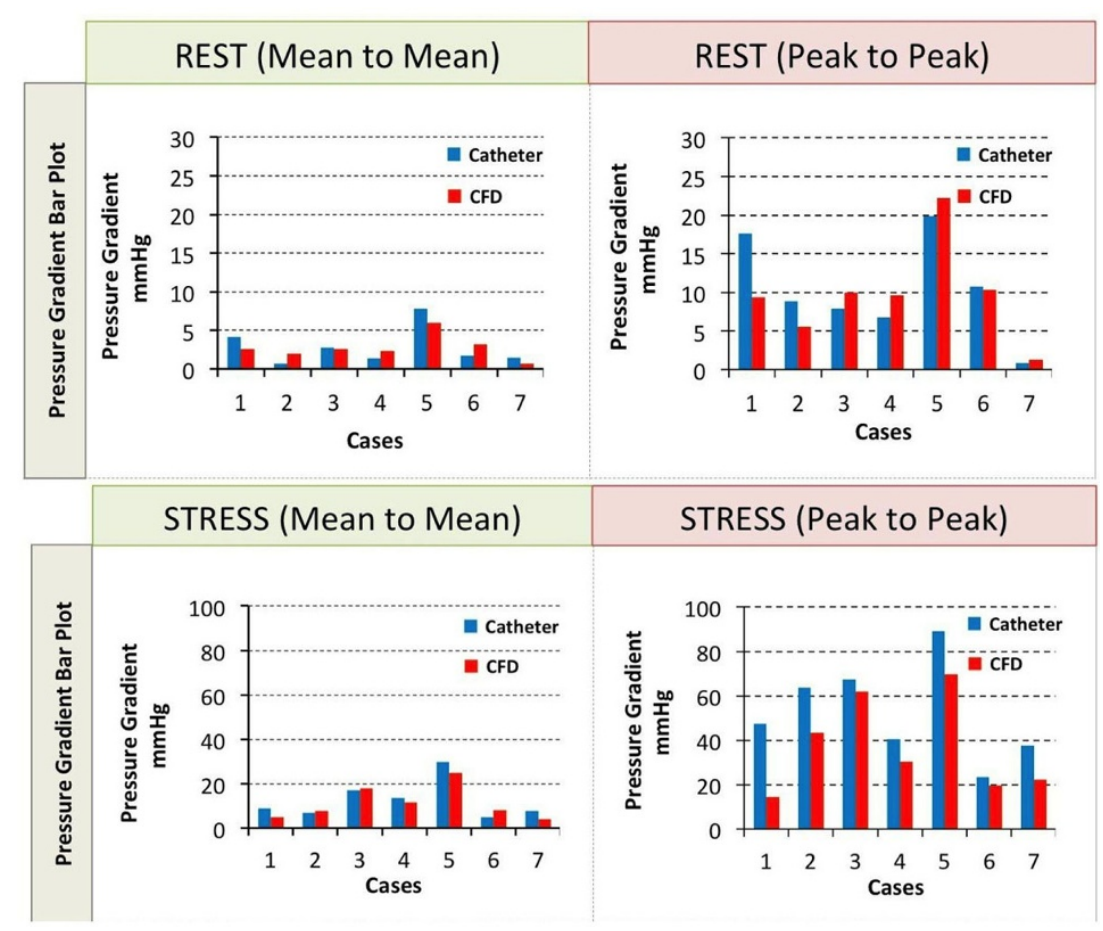

Figure 2 Simulation results, pressure gradient in rest condition (mean to mean and peak to peak) and stress condition (mean to mean and peak to peak), for all cases. 


\section{Authors' details}

${ }^{1}$ Biomedical Imaging Center, Pontificia Universidad Católica de Chile, Santiago, Chile. ${ }^{2}$ Electrical Engineering, Pontificia Universidad Catolica de Chile, Santiago, Chile. ${ }^{3}$ Pediatric Cardiology Unit, Hospital Virgen del Rocio, Seville, Spain. ${ }^{4}$ Cardiovascular Pathology Unit, Institute of Biomedicine of Seville (IBIS), Seville, Spain. ${ }^{5}$ Hannover Medical University, Hannover, Germany. 'Division of Imaging Sciences and Biomedical Engineering, King's College London, London, UK. ${ }^{7}$ Structural and Geotechnical Engineering, Pontificia Universidad Catolica de Chile, Santiago, Chile. ${ }^{8}$ Radiology, School of Medicine, Pontificia Universidad Catolica de Chile, Santiago, Chile. ${ }^{9}$ Surgery and Biomedical Engineering, University of Michigan, Ann Arbor, MI, USA.

Published: 3 February 2015

doi:10.1186/1532-429X-17-S1-Q78

Cite this article as: Sotelo et al:: Pressure gradient prediction in aortic coarctation using a computational-fluid-dynamics model: validation against invasive pressure catheterization at rest and pharmacological stress. Journal of Cardiovascular Magnetic Resonance 2015 17(Suppl 1):Q78.

\section{Submit your next manuscript to BioMed Central} and take full advantage of:

- Convenient online submission

- Thorough peer review

- No space constraints or color figure charges

- Immediate publication on acceptance

- Inclusion in PubMed, CAS, Scopus and Google Scholar

- Research which is freely available for redistribution

Submit your manuscript at www.biomedcentral.com/submit
Ciomed Central 